\title{
openheart Direct oral anticoagulants versus standard triple therapy in atrial fibrillation and PCI: meta-analysis
}

\author{
Natale Daniele Brunetti, ${ }^{1}$ Nicola Tarantino, ${ }^{1}$ Luisa De Gennaro, ${ }^{2}$ Michele Correale ${ }^{3}$ \\ Francesco Santoro, ${ }^{1,4}$ Matteo Di Biase ${ }^{5}$
}

To cite: Brunetti ND, Tarantino N, De Gennaro L, et al. Direct oral anticoagulants versus standard triple therapy in atrial fibrillation and PCl: metaanalysis. Open Heart 2018;5:e000785. doi:10.1136/ openhrt-2018-000785

Received 24 January 2018 Revised 12 April 2018 Accepted 15 May 2018
Check for updates

${ }^{1}$ Department of Medical and Surgical Sciences, University of Foggia, Foggia, Italy ${ }^{2}$ Cardiology Department, San Paolo Hospital, Bari, Italy ${ }^{3}$ Cardiology Department, Ospedali Riuniti University Hospital, Foggia, Italy ${ }^{4}$ Department of Cardiology, Asklepios Klinik Sankt Georg, Hamburg, Germany ${ }^{5}$ GVM Care \& Research, Santa Maria Hospital, Bari, Italy

Correspondence to Dr Natale Daniele Brunetti; nd. brunetti@unifg.it

\section{ABSTRACT}

The coexistence of coronary artery disease and atrial fibrillation (AF) in the same individuals raises great concern about the co-treatment with different antithrombotic agents in the case of percutaneous coronary interventions (PCI). The advent of direct oral anticoagulants (DOACs) revolutionised the therapy of AF; less is known, however, about the safety and efficacy of therapy with DOACs in combination with antiplatelet agents after PCl. We performed a meta-analysis of randomized controlled studies enrolling patients with nonvalvular AF undergoing PCI. We assessed MantelHaenszel pooled estimates of risk ratios (RRs) and 95\% Cls for any bleeding (AB), cardiovascular events (CVE), major bleeding (MB), myocardial infarction (MI), and stent thrombosis (ST) at follow-up: 4849 patients have been included in the analysis. When compared with patients receiving standard triple therapy (vitamin-K antagonists plus double antiplatelet therapy [VKAs plus DAPT]), patients receiving D0ACs (rivaroxaban/dabigatran plus either one or two antiplatelet agents) had a statistically significant lower risk of $A B(R R, 0.66 ; 95 \% \mathrm{Cl}, 0.59-0.75$ $\mathrm{p}<0.00001)$, as well as of MB (RR, $0.59 ; 95 \% \mathrm{Cl}, 0.47-$ $0.73, p<0.00001)$. Equivalent efficacy was found about CVE (RR, 1.03; 95\% Cl, 0.89-1.19, $p=0.69)$, Ml (RR, 1.09; $95 \% \mathrm{Cl}, 0.81-1.45, \mathrm{p}=0.57$ ), while slight although nonstatistically significant increased risk of ST was found (RR, 1.46; $95 \% \mathrm{Cl}, 0.86-2.48, \mathrm{p}=0.16$ ). In conclusion, DOACs are safer than and as effective as warfarin when used in patients with $\mathrm{AF}$ undergoing $\mathrm{PCl}$; dual therapy with DOACs is comparable to triple therapy in terms of safety and efficacy.

\section{INTRODUCTION}

Coronary artery disease (CAD) shares several risk factors (diabetes, hypertension, genetics) with atrial fibrillation $(\mathrm{AF})^{12}$; therefore $\mathrm{CAD}$ and AF may coexist in the same individuals. CAD prevalence ranges between $6.4 \%$ and $46.5 \%$ of AF population. ${ }^{34}$ In spite of that, the antithrombotic treatment used in either condition is different, one based on antiplatelet drugs (CAD), the other on the use of anticoagulants (AF); thus, in case of concomitant therapy, an increased risk of bleeding may occur, with possible severe complications. ${ }^{5}$
The advent of direct oral anticoagulants (DOACs) has revolutionised the therapy of AF; DOACs represent a safer and equally effective alternative to warfarin, as shown in four great trials ${ }^{6-9}$ and some meta-analyses. ${ }^{1011}$

Current guidelines recommend the use of DOACs in case of AF as first-line treatment $^{12}{ }^{13}$; however, warfarin and vitamin-K antagonist (VKAs) are still recommended when double antiplatelet therapy (DAPT) is required, ${ }^{14}$ mainly because of limited data with DOACs available so far.

The PIONEER AF-PCI trial (Open-Label, Randomized, Controlled, Multicenter Study Exploring Two Treatment Strategies of Rivaroxaban and a Dose-Adjusted Oral Vitamin K Antagonist Treatment Strategy in Subjects with Atrial Fibrillation who Undergo Percutaneous Coronary Intervention) ${ }^{16}$ showed that rivaroxaban $15 \mathrm{mg}$ one time per day and $2.5 \mathrm{mg}$ two times per day combined with either a single thienopyridine or DAPT, respectively, was associated with a lower incidence of bleeding compared with VKAs plus DAPT (standard triple therapy), being although equal in terms of cardiovascular death, myocardial infarction (MI) and stroke. These results confirmed the protective effect of rivaroxaban in the setting of acute coronary syndrome as previously shown in the ATLAS ACS 2-TIMI 51 trial (Anti-Xa Therapy to Lower Cardiovascular Events in Addition to Standard Therapy in Subjects with Acute Coronary Syndrome-Thrombolysis in Myocardial Infarction 51), ${ }^{17}$ in line with data from the ROCKET-AF $7 .^{18}$

After the presentation of the RE-DUAL percutaneous coronary interventions (PCI) trial, ${ }^{19}$ which explored the events related to dabigatran 110 or $150 \mathrm{mg}$ and one $\mathrm{P}_{2} \mathrm{Y}_{12}$ antagonist (mostly clopidogrel $75 \mathrm{mg}$ daily), we performed a meta-analysis with the aim to assess the safety and efficacy of DOACs in the clinical setting of patients with non-valvular 


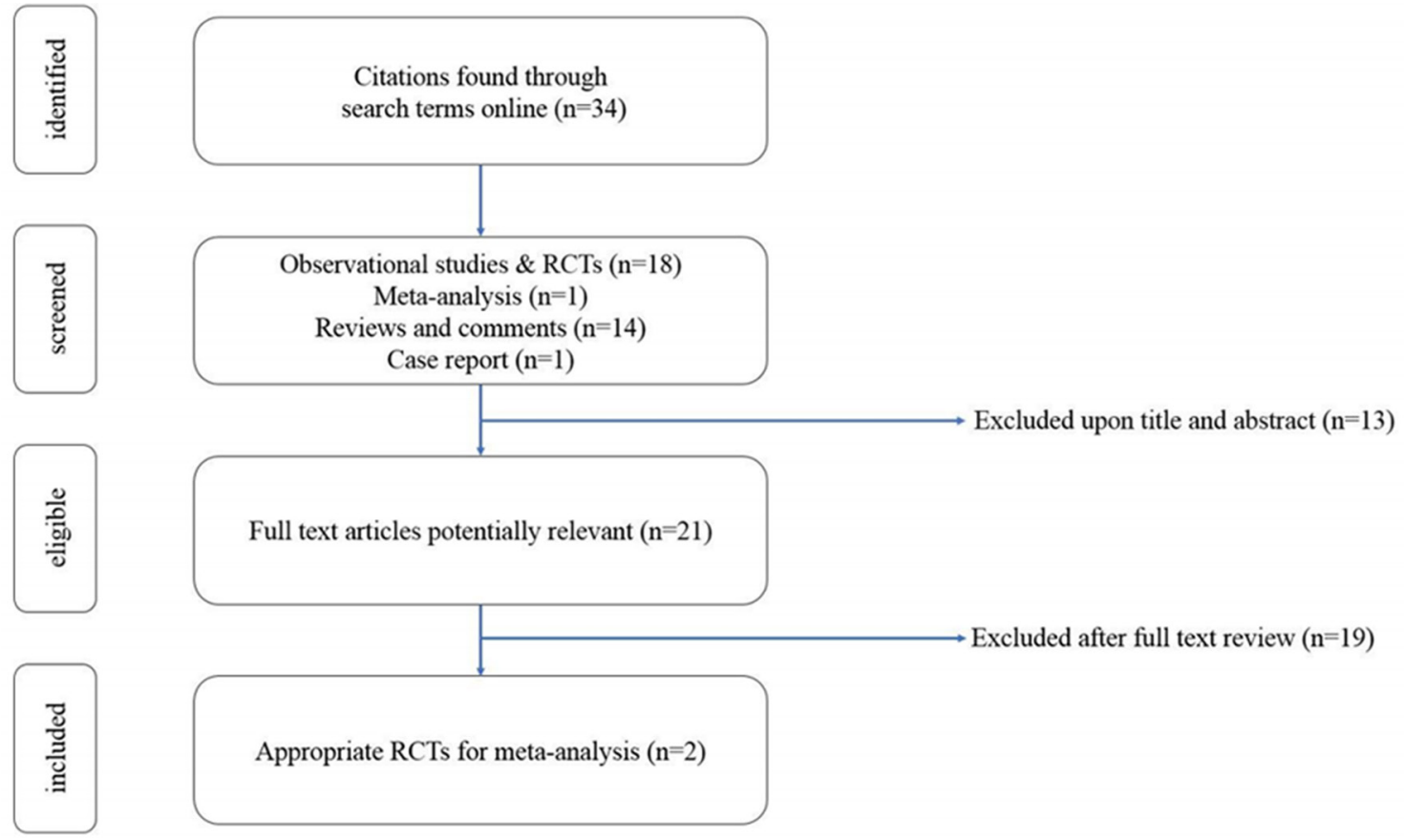

Figure 1 Study selection. RCT, randomised controlled trials.

AF undergone PCI, either in triple antithrombotic therapy or in dual therapy (single antiplatelet agent plus DOAC).

\section{METHODS}

The present meta-analysis was planned, conducted and reported in accordance with currently available statements for the design, analysis and reporting of meta-analyses of randomised and observational studies. We searched PubMed, the Clinical Trials Registry (http:// www.clinicaltrials.gov), the Cochrane Library and Web of Science. Search terms used were 'dabigatran' OR 'rivaroxaban' OR 'clopidogrel' OR 'DAPT' OR 'aspirin' AND 'warfarin' AND 'atrial fibrillation' AND 'PCI' AND 'trials'. Web sites, including acc.org, escardio.org, were also assessed for relevant materials. References of the articles identified in this manner were also searched through to locate additional references that-not identified by the search strategy—might be useful for the purpose.

The search was limited to the English-language publications. We included study-level data derived from randomised, controlled trials comparing DOACs with warfarin in patients with AF undergoing PCI (figure 1).

\section{Study selection}

After study selection, two randomised controlled trials reporting early outcome data of patients with $\mathrm{AF}$ randomised to DOACs or VKAs and treated with antiplatelets after PCI. Data were collected from the two ad hoc trials, PIONEER AF-PCI and RE-DUAL PCI ${ }^{16} 19$ (table 1).

The coprimary endpoints were divided into safety endpoints and efficacy ones. Any bleeding (AB) ranging from severe to minor, and major bleeding (MB) represented the former end points, according to the International Society on Thrombosis and Hemostastis (ISTH) and Thrombolysis in Myocardial Infarction criteria, while MI, stent thrombosis (ST) and cardiovascular events (CVE) constituted the efficacy aims. In order to make uniform the definition of thromboembolic events and to increase the total sample size from each subgroup, the CVE was a composite endpoint, since the two trials used marginally different definition of efficacy endpoints (ie, PIONEER AF-PCI did not consider unplanned revascularisation).

\section{Statistical analysis}

From abstracted data, we calculated the risk ratio (RR) using the Mantel-Haenszel method for each study outcome to allow for pooling of similar outcomes. We obtained the average effects for the outcomes and 95\% CI using a random-effects model. Heterogeneity of the effect across studies was evaluated by means of the Cochrane $\mathrm{Q} \chi^{2}$ and $\mathrm{I}^{2}$ statistics. Lack of homogeneity was assessed for Cochrane $Q \chi^{2}$ test $\mathrm{p}=0.10$ and/or for an $\mathrm{I}^{2}$ statistic $50 \%$.

We computed the $\mathrm{z}$ statistic for each clinical outcome and considered results statistically significant at a $\mathrm{p}<0.05$.

An additional partition of populations enrolled in the study was done, according to dual or triple antithrombotic therapy used; RR calculated in two groups were compared with Breslow-Day test in a per strata analysis.

We also assessed the likelihood of publication bias using funnel plots by displaying individual study RR with 95\% CIs for the endpoints of interest and evaluated it by the Egger regression asymmetry test $(p<0.05$ was here considered as indicative of statistically significant publication bias). 
Arrhythmias and sudden death

\begin{tabular}{|c|c|c|c|c|c|c|}
\hline \multirow{2}{*}{$\begin{array}{l}\text { Study } \\
\text { Subgroup }\end{array}$} & \multicolumn{3}{|c|}{ Pioneer-AF-PCI } & \multicolumn{3}{|l|}{ Re-dual PCI } \\
\hline & $\begin{array}{l}\text { Rivaroxaban } \\
15 \mathrm{mg}+\mathrm{DAPT}\end{array}$ & $\begin{array}{l}\text { Standard } \\
\text { triple therapy }\end{array}$ & $\begin{array}{l}\text { Rivaroxaban } \\
2.5 \mathrm{mg}+\mathrm{DAPT}\end{array}$ & $\begin{array}{l}\text { Dabigatran } \\
150 \mathrm{mg}+\mathrm{P} 2 \mathrm{Y}_{12}\end{array}$ & $\begin{array}{l}\text { Standard triple } \\
\text { therapy }\end{array}$ & $\begin{array}{l}\text { Dabigatran } \\
110 \mathrm{mg}+\mathrm{P} 2 \mathrm{Y}_{12}\end{array}$ \\
\hline $\mathrm{N}$ total bleeding (\%) & 16.8 & 26.7 & 18 & 33.3 & $42.9 / 41.4^{*}$ & 27.1 \\
\hline N MACE (\%) & 6.5 & 5.6 & 6 & 11.8 & $13.4 / 12.8^{\star}$ & 15.2 \\
\hline $\begin{array}{l}\text { Total bleeding HR } \\
\text { (DOAC regimen vs VKAs } \\
\text { regimen) } \dagger\end{array}$ & \multicolumn{2}{|c|}{0.59 (Cl 0.47 to 0.76$)$} & 0.63 (Cl 0.50 to 0.80 ) & \multicolumn{2}{|c|}{0.72 (CI 0.61 to 0.84$)$} & 0.54 (Cl 0.46 to 0.63 ) \\
\hline$P$ value & \multicolumn{2}{|l|}{$<0.001$} & $<0.001$ & \multicolumn{2}{|l|}{$<0.001$} & $<0.001$ \\
\hline $\begin{array}{l}\text { MACE HR } \\
\text { (DOAC regimen vs VKAs } \\
\text { regimen) } \dagger\end{array}$ & \multicolumn{2}{|c|}{1.08 (Cl 0.69 to 1.68$)$} & 0.93 (Cl 0.59 to 1.48 ) & \multicolumn{2}{|c|}{0.89 (Cl 0.67 to 1.14$)$} & 1.13 (Cl 0.90 to 1.43 ) \\
\hline$P$ value & \multicolumn{2}{|l|}{0.75} & 0.76 & \multicolumn{2}{|l|}{0.44} & 0.30 \\
\hline
\end{tabular}

Cumulative incidence of one primary safety and one secondary efficacy endpoint calculated in the two trials. $\mathrm{HRS}$ are intended with $95 \% \mathrm{Cl}$.

${ }^{*}$ The two values refer to the number of patients used for HR in dabigatran 150/dabigatran $110 \mathrm{mg}$ arms.

†HRs are calculated from comparison of single subgroups couples (ie, rivaroxaban $15 \mathrm{mg}+\mathrm{DAPT}$ vs standard triple therapy).

AF, atrial fibrillation; DAPT, double antiplatelet therapy; DOAC, advent of direct oral anticoagulants; MACE, major cardiovascular events;

$\mathrm{PCl}$, percutaneous coronary interventions; VKAs, vitamin $\mathrm{K}$ antagonists.

\section{RESULTS}

\section{Overall analysis: safety endpoints}

A population of 4849 patients was finally included in the meta-analysis. When compared with patients receiving standard triple therapy, patients receiving DOACs had a significantly lower risk of $\mathrm{AB}(\mathrm{RR}=0.66 ; 95 \% \mathrm{CI} 0.59$ to $0.75, \mathrm{p}<0.00001)$ and of $\mathrm{MB}(\mathrm{RR}=0.59 ; 95 \% \mathrm{CI} 0.47$ to 0.73 , $\mathrm{p}<0.00001)$, without significant statistical heterogeneity among subgroups (Cochrane $Q \mathrm{p}=0.69 ; \mathrm{I}^{2}=0 \%$ for $\mathrm{AB}$ and $\mathrm{p}=0.60 ; \mathrm{I}^{2}=0 \%$ for $\mathrm{MB}$ ) (figures 2 and 3 ).

\section{Overall analysis: efficacy endpoints}

Equivalent efficacy was found comparing DOACs with warfarin regarding CVE ( $R R=1.03 ; 95 \%$ CI 0.89 to 1.19 , $\mathrm{p}=0.69)$ and MI ( $\mathrm{RR}=1.09$; $95 \%$ CI 0.81 to 1.45 , $\mathrm{p}=0.57)$; a higher although non-statistically significant risk of ST

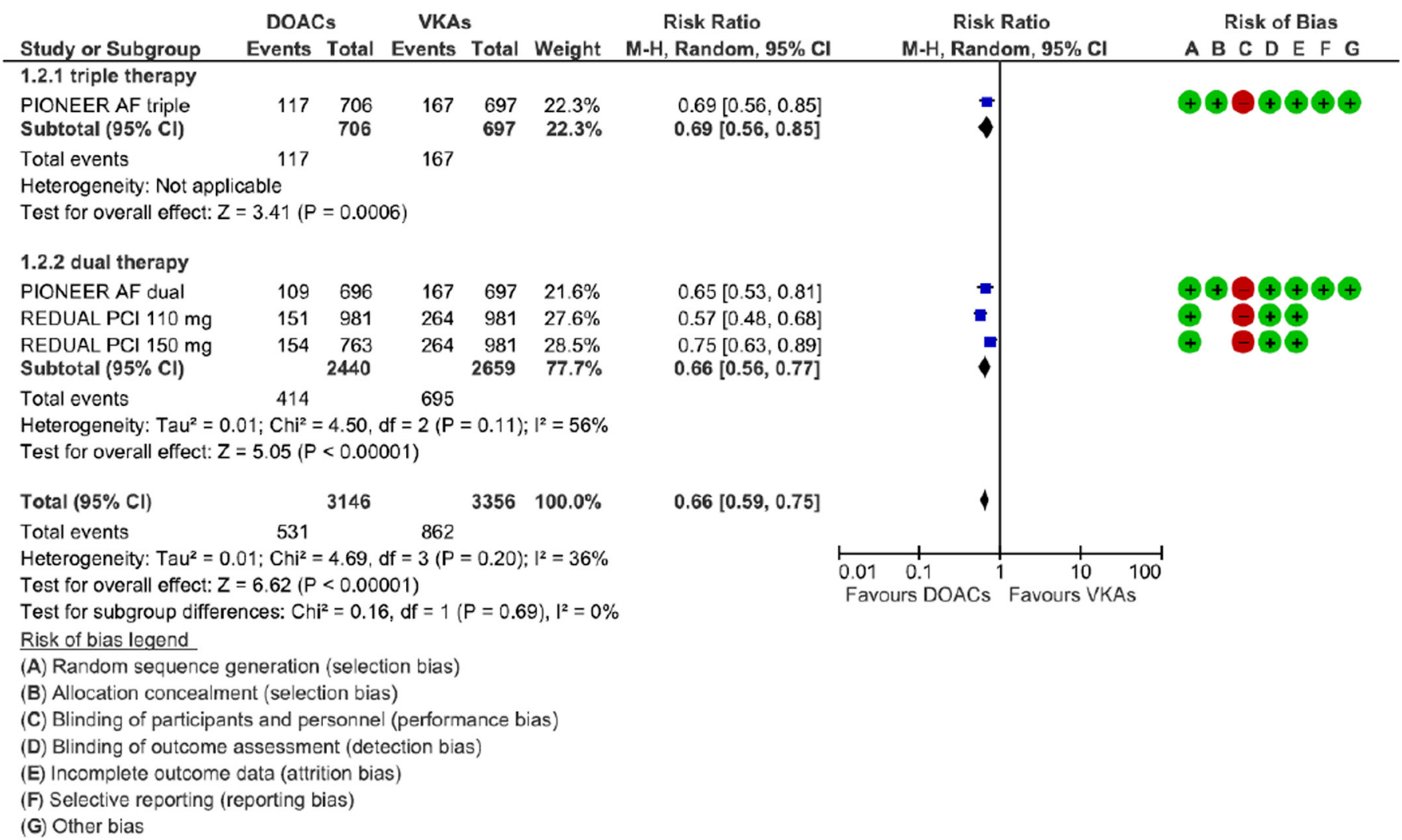

Figure 2 Forest plot illustrating the risk ratio of any bleeding and GRADE assessment. AF, atrial fibrillation; DOAC, advent of direct oral anticoagulants; $\mathrm{PCl}$, percutaneous coronary interventions; VKAs, vitamin K antagonists. 


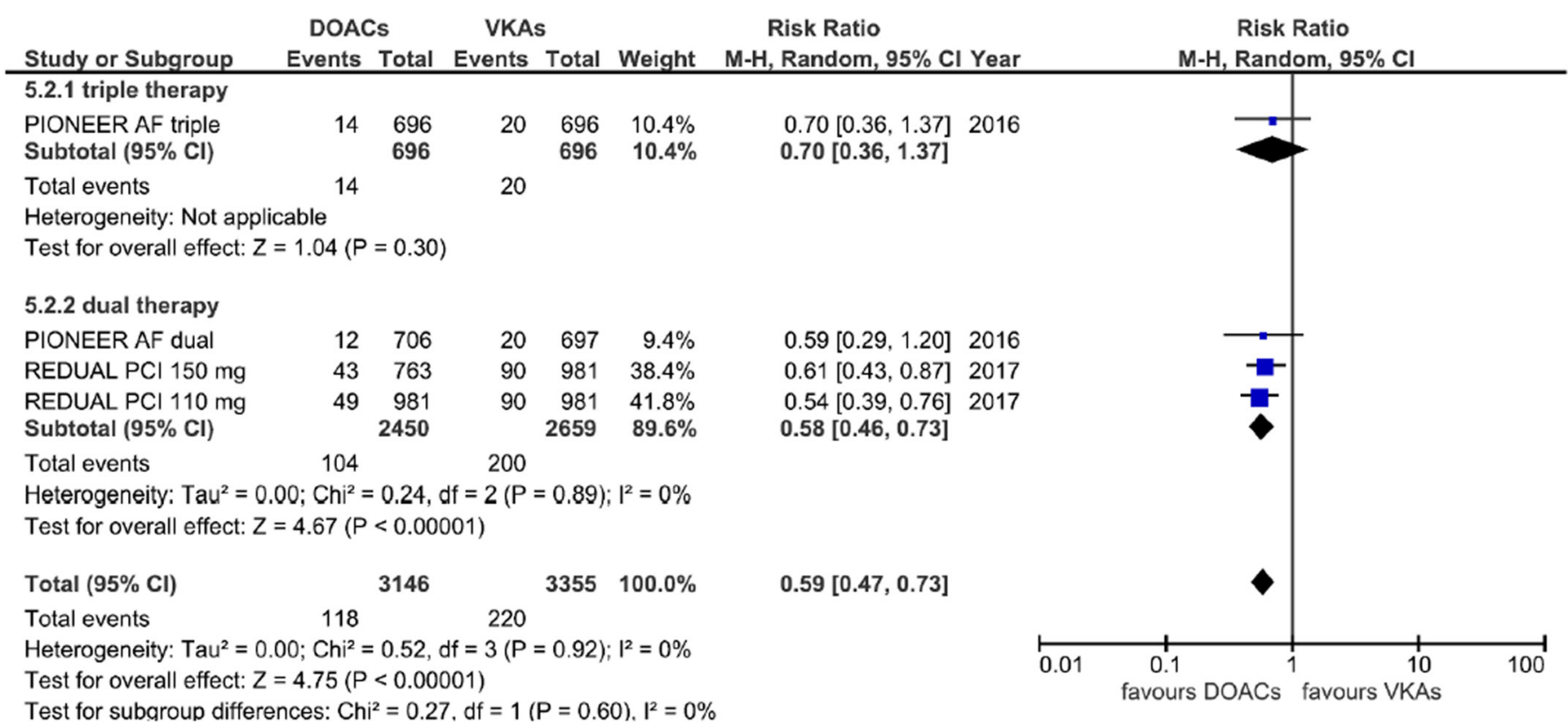

Figure 3 Forest plot illustrating the risk ratio of major bleeding. AF, atrial fibrillation; DOAC, advent of direct oral anticoagulants; $\mathrm{PCl}$, percutaneous coronary interventions; VKAs, vitamin $\mathrm{K}$ antagonists.

was also found $(\mathrm{RR}=1.46 ; 95 \% \mathrm{CI} 0.86$ to $2.48, \mathrm{p}=0.16)$, without any subgroup difference (Cochrane $\mathrm{Q} p=0.85$, $0.29,0.98$ and $\mathrm{I}^{2}=0 \%, 12.2 \%$ and $0 \%$ for CVE, MI and ST, respectively) (figures 4-6).

\section{Triple versus dual therapy subgroup analysis of safety and efficacy endpoints}

We observed similar results analysing the two antithrombotic regimens used in the two studies, triple therapy (used just in the PIONEER study) versus dual therapy, used in both ( $p$ for interaction n.s.). Egger's test did not find any significant publication bias (p n.s.); funnel plot was reported in figure 7 .

\section{DISCUSSION}

In this study, we performed the first meta-analysis about the use of DOACs compared with VKAs in patients with non-valvular AF after PCI. Our results highlight three important points: first, the use of DOACs is generally safer than and as effective as warfarin in such patients; second, dual therapy with DOACs is as safer than and as effective as triple therapy with warfarin; third, dual therapy with DOACs is as safe as and as effective as triple therapy with DOACs in patients with AF treated with PCI.

Oral anticoagulation is reported in a minority of patients with overt $\mathrm{CAD}(0.2 \%-5 \%),{ }^{4}$ but, conversely,

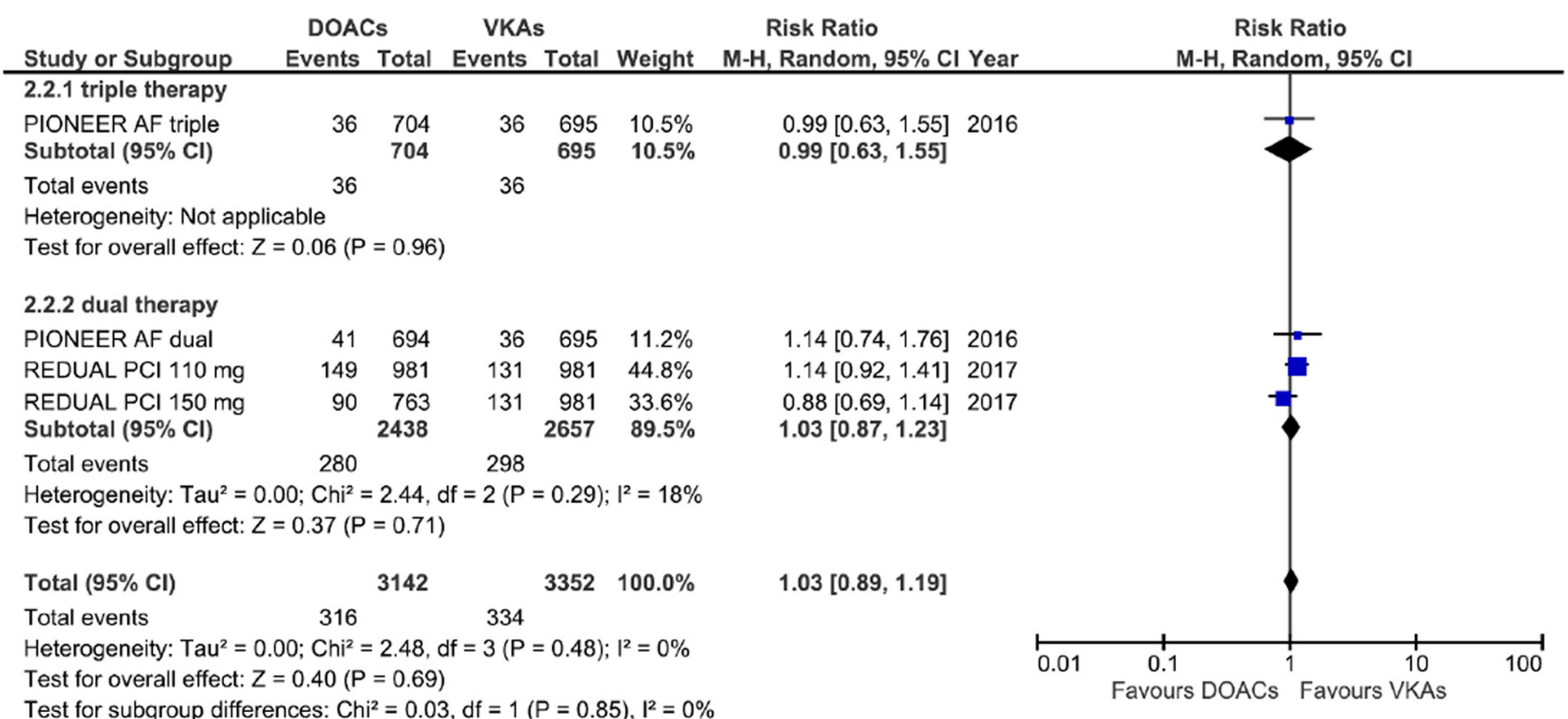

Figure 4 Forest plot illustrating the risk ratio of total cardiovascular event. AF, atrial fibrillation; DOAC, advent of direct oral anticoagulants; $\mathrm{PCl}$, percutaneous coronary interventions; VKAs, vitamin $\mathrm{K}$ antagonists. 


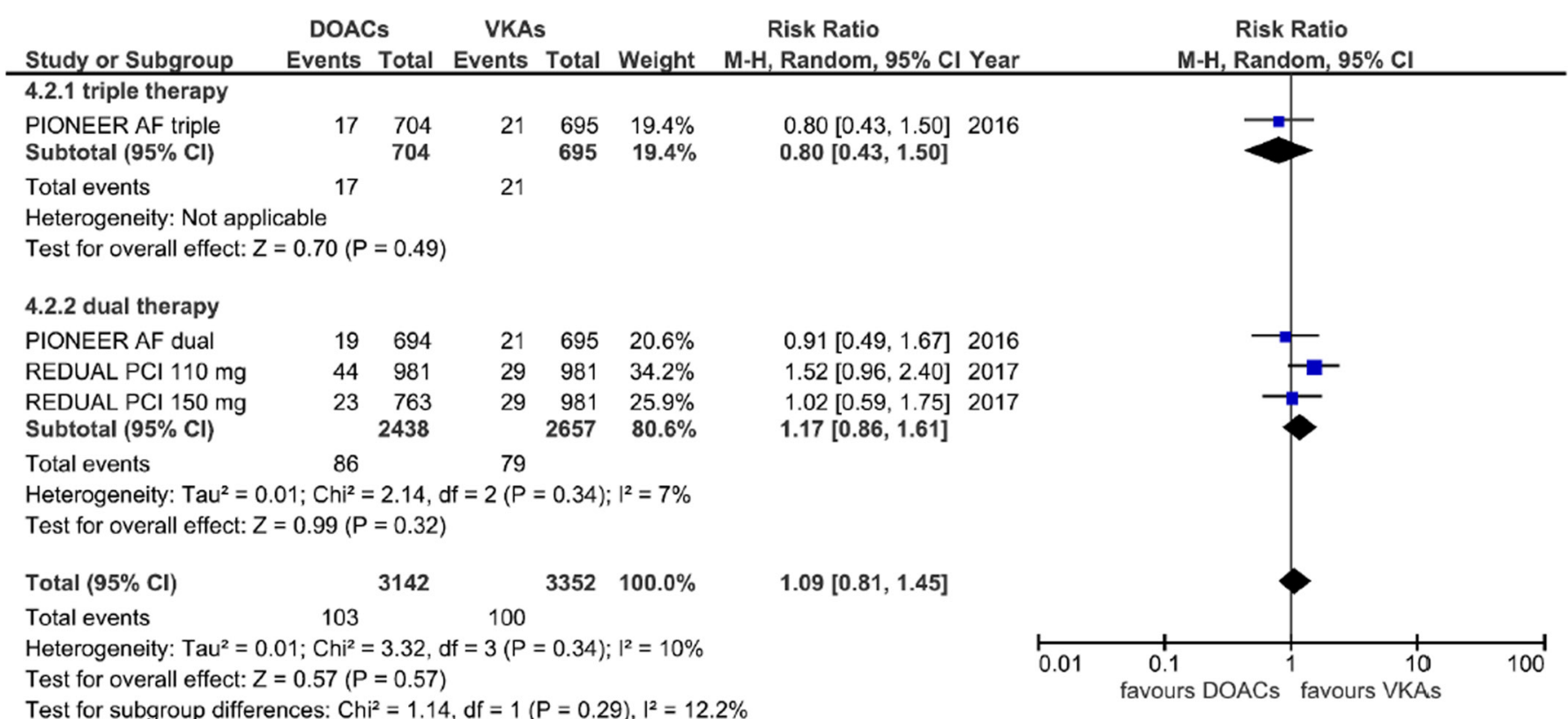

Figure 5 Forest plot illustrating the risk ratio of myocardial infarction. AF, atrial fibrillation; DOAC, advent of direct oral anticoagulants; $\mathrm{PCl}$, percutaneous coronary interventions; VKAs, vitamin $\mathrm{K}$ antagonists.

concomitant potentially revascularisable $\mathrm{CAD}$ may be found in about one-third of patients with $\mathrm{AF}^{3}$; therefore, the management of antithrombotic therapy is of utmost importance in clinical practice. The latest European guidelines ${ }^{14}$ suggest the use VKAs plus aspirin and clopidogrel (standard triple therapy) for at least 1 month after PCI, regardless the type of stent, extendable up to 6 months in case of higher ischaemic risk such as prior ST, multivessel disease, technical considerations (Class IIa LOE B). Dual antithrombotic therapy with VKA plus clopidogrel is accepted in case of elevated bleeding risk (Class IIa LOE A). A similar consensus is shared by the American College of Cardiology. ${ }^{15}$
The only DOAC explicitly considered by European Society of Cardiology is the rivaroxaban $15 \mathrm{mg}$ one time per day added to aspirin and clopidogrel (Class IIb LOE $\mathrm{B})$ and generally whatever DOAC should be prescribed to the lowest dose available (Class IIa LOE C). Furthermore, third generation $\mathrm{P}_{2} \mathrm{Y}_{12}$ inhibitors are not recommended on the base of a presumed higher risk of bleeding (Class III LOE C). ${ }^{14}$

Dual antiplatelet therapy is inadequate to protect against thromboembolic complication of $\mathrm{AF}^{20}$; on the other hand, triple therapy with VKAs nearly doubles the risk of bleeding, ${ }^{21}$ regardless the duration of the treatment as shown in the ISAR-TRIPLE trial. ${ }^{22}$ VKAs were

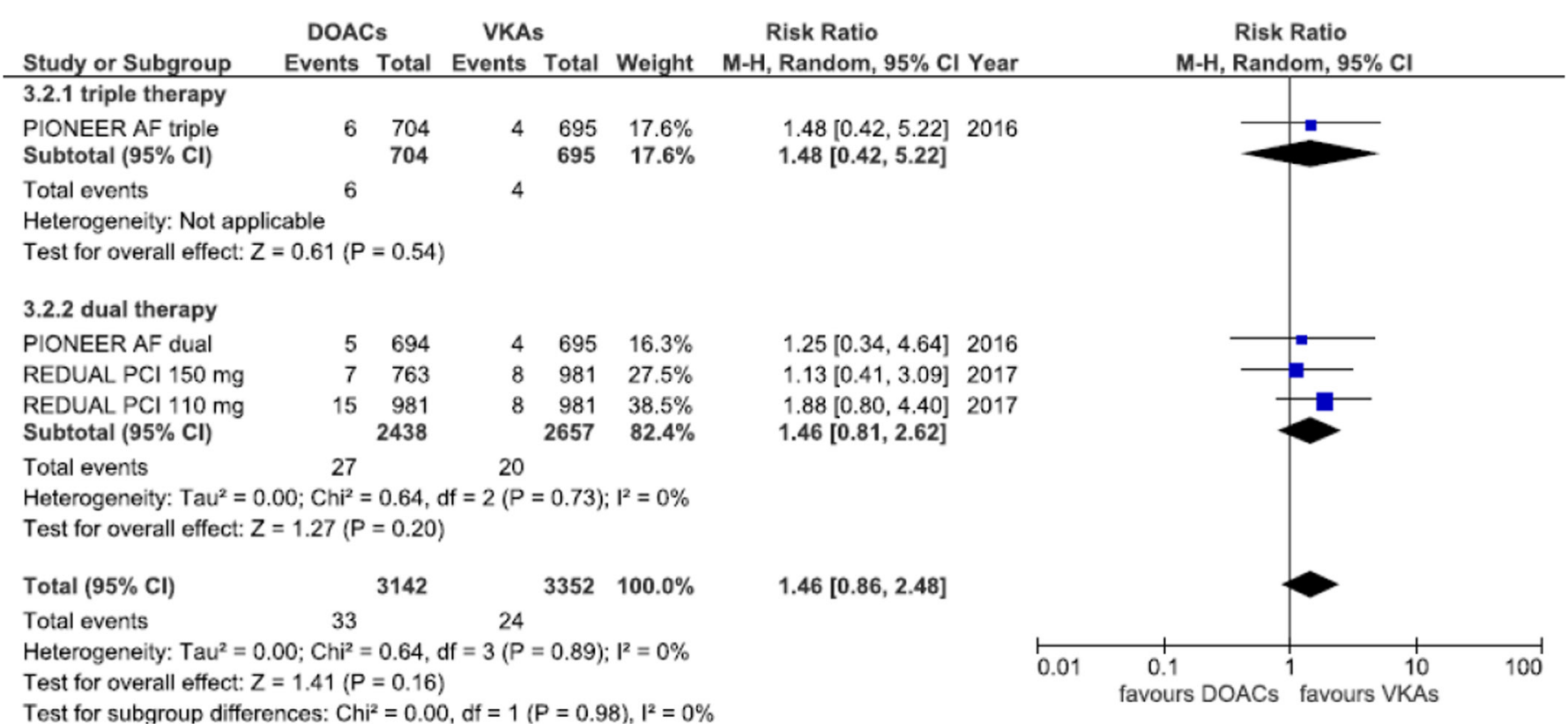

Figure 6 Forest plot illustrating risk ratio of stent thrombosis. AF, atrial fibrillation; DOAC, advent of direct oral anticoagulants; $\mathrm{PCl}$, percutaneous coronary interventions; VKAs, vitamin K antagonists. 


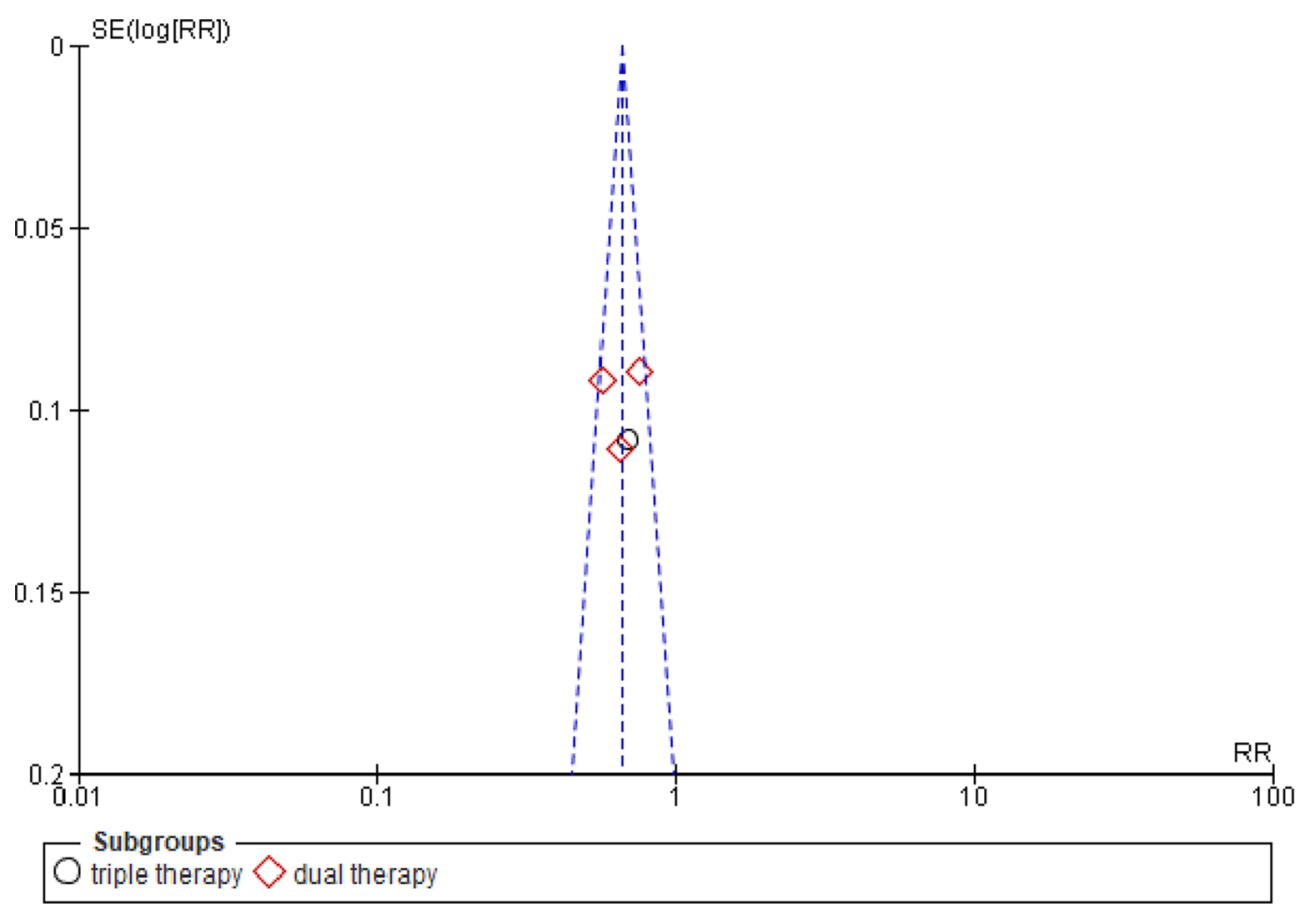

Figure 7 Funnel plot showing absence of publication bias in the studies. RR, risk ratio.

preferred to DOACs so far because of the absence of data on DOACs coming from dedicated randomised clinical trials exploring their safety and efficacy in subjects with AF treated with PCI. The rationale supporting the use of DOACs in PCI and AF stems from the already witnessed great safety in phase III original trials, ${ }^{6-9}$ probably based on their ability to inhibit one single clotting factor (Xa or prothrombin) compared with extensive effect on secondary hemostasis exerted by VKAs, which also exhibit a narrower therapeutic window. ${ }^{23}$ Safety of DOACs was further confirmed even in AF and PCI in the abovementioned two randomised trials (table 1) and in our meta-analysis, where we found lower rates of $\mathrm{AB}$ and of MB.

With regard to efficacy endpoints, PIONEER AF-PCI and RE-DUAL PCI were largely underpowered to demonstrate with statistical certainty any differences between DOACs based regimen and VKAs one, however both the treatment strategies were equally effective in terms of CVE rate, including MI, stroke and cardiac revascularisation. ST was the only endpoint showing a slight incidence increase in DOACs subgroups versus VKA patients, although interval of confidence was quite broad and $p$ value was not significant. The reason for such finding may be just partly hypothesised: the vast majority $(>90 \%)$ of the populations enrolled in the meta-analysis was treated with clopidogrel, which is currently the second choice $\mathrm{P}^{2} \mathrm{Y}_{12}$ inhibitor. ${ }^{14}$ Third generation thienopyridine, which are more protective against ST, were not extensively prescribed in PIONEER AF-PCI and REDUAL PCI studies: less than $6 \%$ of patients from the former ${ }^{16}$ and only ticagrelor in $11 \%$ from the latter. ${ }^{19}$ Additionally, it is unknown the percentage of ST in bare metal versus drug eluting stents.
Even more interesting are the evidence that dual antithrombotic therapy may be as effective and safe as triple therapy. These data seem in line with those coming from WOEST study where patients assigned to double therapy with clopidogrel and VKA experienced a lower risk of bleeding episodes compared with DAPT plus oral anticoagulant arm ( $R R=0.36)$, whereas thromboembolic events were overall comparable except for ischaemic stroke which almost resulted statistically significant inferior in the double treatment group $(\mathrm{RR}=0.25) .{ }^{24}$

Larger populations, however, are required to confirm this preliminary analysis; such larger populations, also including ongoing studies with apixaban (NCT02635230) and edoxaban (NCT02866175), would be perhaps able to reach the statistical significance with respect to composite efficacy endpoint. ${ }^{25} 26$

\section{LIMITATIONS}

Dose DOACs and regimen of antithrombotic therapy used in the studies included in the meta-analysis are different: the PIONEER AF-PCI study used a triple therapy with reduced dose of rivaroxaban and a dual therapy with standard low dose, the REDUAL PCI study standard dose of dabigatran in dual antithrombotic therapy.

Follow-up periods were different, 12 months for the PIONEER AF-PCI study vs 14 months for the REDUAL PCI study. The number of patients who withdrew the consent or discontinued the treatment was around $20 \%$ in the PIONEER-AF-PCI. ${ }^{16}$

Finally, less is known about compliance, clinical profile of patients who experienced any events, drugdrug interaction and bridging with heparin in patients 
treated with warfarin, which is known to increase the risk thromboembolism. ${ }^{27}$

Data on mortality were not used for this meta-analysis because PIONEER AF-PCI study provided data on cardiovascular mortality while REDUAL PCI study on total mortality.

Some doses of DOAC were not previously documented for the prevention of AF thromboembolic complications.

The control group was duplicated for both studies with the aim to analyse subgroups of both studies.

\section{CONCLUSION}

DOACs are safer than and as effective as warfarin when used in patients with AF undergoing PCI; dual therapy with DOACs is comparable to triple therapy in terms of safety and efficacy.

Contributors $\mathrm{LDeG}$ and MC retrieved data. MDiB supervised the paper. NDB and FS performed statistical analysis. NDB and NT wrote the paper.

Funding The authors have not declared a specific grant for this research from any funding agency in the public, commercial or not-for-profit sectors.

Competing interests None declared.

Patient consent Not required.

Provenance and peer review Not commissioned; externally peer reviewed.

Open access This is an open access article distributed in accordance with the Creative Commons Attribution Non Commercial (CC BY-NC 4.0) license, which permits others to distribute, remix, adapt, build upon this work non-commercially, and license their derivative works on different terms, provided the original work is properly cited and the use is non-commercial. See: http://creativecommons.org/ licenses/by-nc/4.0/

(c) Article author(s) (or their employer(s) unless otherwise stated in the text of the article) 2018. All rights reserved. No commercial use is permitted unless otherwise expressly granted.

\section{REFERENCES}

1. Hohl M, Lau DH, Müller A, et al. Concomitant obesity and metabolic syndrome add to the atrial arrhythmogenic phenotype in male hypertensive rats. J Am Heart Assoc 2017;6:e006717.

2. Verweij N, Eppinga RN, Hagemeijer Y, et al. Identification of 15 novel risk loci for coronary artery disease and genetic risk of recurrent events, atrial fibrillation and heart failure. Sci Rep 2017;7:2761.

3. Akao M. Atrial fibrillation and coronary artery disease: resembling twins? J Cardiol 2014;63:169-70.

4. Michniewicz E, Mlodawska E, Lopatowska P, et al. Patients with atrial fibrillation and coronary artery disease - Double trouble. Adv Med Sci 2018;63:30-5.

5. Lamberts M, Olesen JB, Ruwald MH, et al. Bleeding after initiation of multiple antithrombotic drugs, including triple therapy, in atrial fibrillation patients following myocardial infarction and coronary intervention: a nationwide cohort study. Circulation 2012;126:1185-93.

6. Connolly SJ, Ezekowitz MD, Yusuf S, et al. Dabigatran versus warfarin in patients with atrial fibrillation. $N$ Engl J Med 2009;361:1139-51.

7. Patel MR, Mahaffey KW, Garg J, et al. Rivaroxaban versus warfarin in nonvalvular atrial fibrillation. N Engl J Med 2011;365:883-91.

8. Granger $\mathrm{CB}$, Alexander JH, McMurray JJ, et al. Apixaban versus warfarin in patients with atrial fibrillation. $N$ Engl $J$ Med 2011;365:981-92.
9. Giugliano RP, Ruff CT, Braunwald E, et al. Edoxaban versus warfarin in patients with atrial fibrillation. N Engl J Med 2013;369:2093-104.

10. Sardar P, Chatterjee S, Wu WC, et al. New oral anticoagulants are not superior to warfarin in secondary prevention of stroke or transient ischemic attacks, but lower the risk of intracranial bleeding: insights from a meta-analysis and indirect treatment comparisons. PLoS One 2013;8:e77694.

11. Vallakati A, Sharma A, Madmani M, et al. Efficacy and safety of nove oral anticoagulants for atrial fibrillation ablation: an updated metaanalysis. Cardiol Ther 2016;5:85-100.

12. Kirchhof $P$, Benussi $S$, Kotecha D, et al. ESC Guidelines for the management of atrial fibrillation developed in collaboration with EACTS. Eur Heart J 2016;2016:2893-962.

13. January CT, Wann LS, Alpert JS, et al. 2014 AHA/ACC/ HRS guideline for the management of patients with atrial fibrillation: executive summary: a report of the American College of Cardiology/American Heart Association Task Force on practice guidelines and the Heart Rhythm Society. Circulation 2014;130:2071-104.

14. Valgimigli M, Bueno $\mathrm{H}$, Byrne RA, et al. ESC focused update on dual antiplatelet therapy in coronary artery disease developed in collaboration with EACTS: the task force for dual antiplatelet therapy in coronary artery disease of the European Society of Cardiology (ESC) and of the European Association for Cardio-Thoracic Surgery (EACTS). Eur Heart J 2017;26.

15. Levine GN, Bates ER, Bittl JA, et al. ACC/AHA guideline focused update on duration of dual antiplatelet therapy in patients with coronary artery disease: A report of the American College of Cardiology/American Heart Association Task Force on Clinical Practice Guidelines. J Thorac Cardiovasc Surg 2016;2016:1243-75.

16. Gibson CM, Mehran R, Bode C, et al. Prevention of bleeding in patients with atrial fibrillation undergoing PCI. N Engl J Med 2016;375:2423-34.

17. Cavender MA, Gibson CM, Braunwald E, et al. The effect of rivaroxaban on myocardial infarction in the ATLAS ACS 2 - TIMI 51 trial. Eur Heart J Acute Cardiovasc Care 2015;4:468-74.

18. Mahaffey KW, Stevens SR, White HD, et al. Ischaemic cardiac outcomes in patients with atrial fibrillation treated with vitamin $\mathrm{K}$ antagonism or factor Xa inhibition: results from the ROCKET AF trial. Eur Heart J 2014;35:233-41.

19. Cannon CP, Bhatt DL, Oldgren J, et al. Dual antithrombotic therapy with dabigatran after $\mathrm{PCl}$ in atrial fibrillation. N Engl J Med 2017;377:1513-24.

20. Tawfik A, Bielecki JM, Krahn M, et al. Systematic review and network meta-analysis of stroke prevention treatments in patients with atrial fibrillation. Clin Pharmacol 2016;8:93-107.

21. Agarwal N, Jain A, Mahmoud AN, et al. Safety and efficacy of dual versus triple antithrombotic therapy in patients undergoing percutaneous coronary intervention. Am J Med 2017; pii: S00029343:30401-1.

22. Fiedler KA, Maeng M, Mehilli J, et al. Duration of triple therapy in patients requiring oral anticoagulation after drug-eluting stent implantation: The ISAR-TRIPLE Trial. J Am Coll Cardiol 2015;65:1619-29.

23. Wang Y, Bajorek B. New oral anticoagulants in practice: pharmacological and practical considerations. Am J Cardiovasc Drugs 2014;14:175-89.

24. Dewilde WJ, Oirbans T, Verheugt FW, et al. Use of clopidogrel with or without aspirin in patients taking oral anticoagulant therapy and undergoing percutaneous coronary intervention: an open-label, randomised, controlled trial. Lancet 2013;381:1107-15.

25. USNIH. What is the optimal antiplatelet and anticoagulant therapy in patients with oral anticoagulation undergoing revasculariSaTion 2. 2017. https://clinicaltrials.gov/ct2/show/NCT02635230

26. USNIH. Edoxaban Treatment Versus Vitamin K Antagonist in Patients With Atrial Fibrillation Undergoing Percutaneous Coronary Intervention (ENTRUST-AF-PCI). 2017. https://clinicaltrials.gov/ct2/ show/NCT02866175

27. Sjögren V, Grzymala-Lubanski B, Renlund H, et al. Safety and efficacy of bridging with low-molecular-weight heparin during temporary interruptions of warfarin: a register-based cohort study. Clin Appl Thromb Hemost 2017;23:961-6. 